Western University

Scholarship@Western

Aboriginal Policy Research Consortium International (APRCi)

$4-2012$

\title{
Magic and superstition in baseball in Taiwan: an examination of the Puyama aborigines' use of the betel nut
}

Junwei Yu

Follow this and additional works at: https://ir.lib.uwo.ca/aprci

Part of the Sports Studies Commons

Citation of this paper:

Yu, Junwei, "Magic and superstition in baseball in Taiwan: an examination of the Puyama aborigines' use of the betel nut" (2012).

Aboriginal Policy Research Consortium International (APRCi). 183.

https://ir.lib.uwo.ca/aprci/183 
This article was downloaded by: [University of Western Ontario]

On: 07 December 2012, At: 07: 45

Publisher: Routledge

Informa Ltd Registered in England and Wales Registered Number: 1072954 Registered

office: Mortimer House, 37-41 Mortimer Street, London W1T 3J H, UK

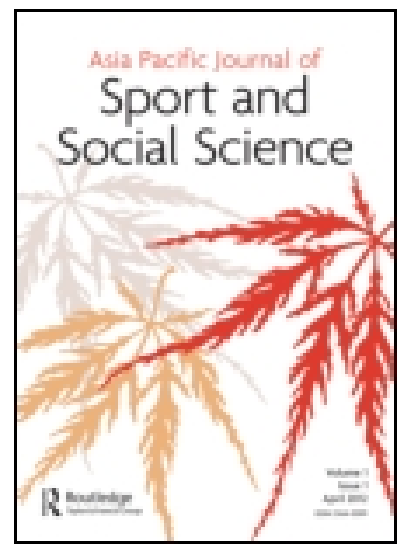

\title{
Asia Pacific J ournal of Sport and Social Science
}

Publication details, including instructions for authors and subscription information:

http:// www.tandfonline.com/loi/ rass20

\section{Magic and superstition in baseball in Taiwan: an examination of the Puyama aborigines' use of the betel nut}

\author{
J unwei $Y u^{a}$ \\ Physical Education and Sport, Taiwan \\ Version of record first published: 05 J ul 2012.
}

${ }^{a}$ Department of Physical Education, National Taiwan University of

To cite this article: J unwei Yu (2012): Magic and superstition in baseball in Taiwan: an examination of the Puyama aborigines' use of the betel nut, Asia Pacific J ournal of Sport and Social Science, 1:1, 8-21

To link to this article: http:// dx. doi.org/ 10.1080/21640599.2012.701372

PLEASE SCROLL DOWN FOR ARTICLE

Full terms and conditions of use: http://www.tandfonline.com/page/terms-and-conditions This article may be used for research, teaching, and private study purposes. Any substantial or systematic reproduction, redistribution, reselling, loan, sub-licensing, systematic supply, or distribution in any form to anyone is expressly forbidden.

The publisher does not give any warranty express or implied or make any representation that the contents will be complete or accurate or up to date. The accuracy of any instructions, formulae, and drug doses should be independently verified with primary sources. The publisher shall not be liable for any loss, actions, claims, proceedings, demand, or costs or damages whatsoever or howsoever caused arising directly or indirectly in connection with or arising out of the use of this material. 


\title{
Magic and superstition in baseball in Taiwan: an examination of the Puyama aborigines' use of the betel nut
}

\author{
Junwei $\mathrm{Yu}^{*}$
}

Department of Physical Education, National Taiwan University of Physical Education and Sport, Taiwan

\begin{abstract}
Much work has been published on the place of rituals in numerous areas of life with reference both to general activities and, more specifically, to sport. As yet, however, there has been no significant study of the use of magic by and on behalf of players in Taiwan where baseball can legitimately be described as the national sport. This article seeks to fill that void by focusing in particular on the practices of the island's Puyama aboriginal people and the use of the betel nut to cast spells on opponents. The data for this study were collected during two research trips to Taidong County, where the Puyuma have traditionally used betel nuts on the baseball field for magical purposes. It is apparent from a series of personal reminiscences that the use of the betel nut spell had an influence on Puyama players and opponents alike. Its passing owes much to the increased acceptance of seemingly more rational ways of instilling confidence in athletes. The author argues, however, that the modern recourse to the sport sciences has much in common with the Puyama belief in the power of the betel nut.
\end{abstract}

Keywords: magic; superstition; Taiwan; aborigines; baseball

\section{Introduction}

Since 1890, when James G. Frazer first published two volumes of The Golden Bough: A Study of Magic and Religion (1993), anthropologists have shown significant interest in the place of magic and ritual in human societies. Not least of these is Bronislaw Malinowski, whose 1954 work on fishermen from the Trobriand Islands in the Pacific Ocean indicated that ritual superstition becomes particularly important in the face of difficult conditions and uncertainty. Although rituals had no direct bearing on the outcome of the fishermen's endeavours, they enabled the fishermen to create and maintain a sense of being in control.

Much work has been published on the place of rituals in numerous areas of life, although it should be added that most of this has been conducted not by sociologists or anthropologists, but by psychologists writing with reference both to general activities (Rudski \& Edwards, 2007) and, more specifically, to sport (Bleak \& Frederick, 1998; Schippers \& Van Lange, 2006; Wright \& Erdal, 2008). Bleak and Frederick (1998, p. 2) state that 'the role of superstitious ritual in sport is not new' and cite both Malinowski and Gardiner (1925) in support of this claim. As Neal (1982) noted, however, theorizing the topic has commonly raised just as many questions as it has answered. That said, analysis of superstitions, magic and rituals that draws upon Malinowski has been developed in relation to both professional baseball (Gmelch, 1971, 1992) and college baseball

*Email: chunweiyu@yahoo.com 
(Ciborowski, 1997), while Bradley and Gordon (2007, 2010) have explored supernatural rumours and stories surrounding professional baseball and its ballparks. In addition, Burger and Lynn (2005) have compared the superstitious behaviours of American and Japanese players. As yet, however, there has been no significant study of the use of magic by and on behalf of players in Taiwan, where baseball can legitimately be described as the national sport. This article seeks to fill that void by focusing in particular on the practices of the island's Puyama aboriginal people. With specific reference to baseball, Gmelch has suggested that 'unlike many forms of primitive magic, baseball magic is usually performed to achieve one's own end and not to block someone else's' (2009, p. 6). However, such a practice is in stark contrast, as we shall demonstrate, to the 'black magic' of the Puyama.

Considerable research has been done on the place of aborigines in Taiwanese baseball, both historically (Gao, 1995a, 1995b; Wang, 1994; Yu, 2007a, 2007b; Yu \& Bairner, 2010; Zhang, 2007) and sociologically (Lin \& Zhu, 2009; Qiu, 2003; Qiu, 2008; Yu \& Bairner, in press), not least given the fact that indigenous people constitute only $2 \%$ of the population of Taiwan but provide over $40 \%$ of players in the domestic professional league. Despite the plethora of research, however, there has as yet been no serious social scientific study of the relationship between aboriginal folk religion and baseball.

The data for this study was collected during two research trips to Taidong County, where the Puyuma have traditionally used betel nuts on the baseball field for magical purposes. The methods used in seeking to understand this cultural phenomenon included archival research, observation and interviews. The author conducted a total of 11 face-toface semi-structured interviews, with four coaches, three retired players, three current players and one retired school principal. In addition, another current player was interviewed by telephone. Apart from the retired principal and one current player, who were Han Chinese, the interviewees were of aboriginal origin - either from the Amis, Puyuma, or Bunun peoples. Each face-to-face interview usually lasted about an hour, and was audio recorded. The researcher also attended a palakuan (men's meeting hall for the Puyuma tribe) to take part in a traditional ceremony for which a shaman and his assistant prepared betel nuts.

\section{Aborigines in Taiwan}

The term 'aboriginal' refers, in Taiwan, to the earliest groups of people who arrived on the island and inhabited it before the arrival of the Han Chinese, who only systematically started to migrate from mainland China in the seventeenth century. Although there are several theories relating to the origins of Taiwan's indigenous population, research in the fields of linguistics, archeology and anthropology in recent years has suggested that their ancestors may have been living on the island since approximately 6000 years before large-scale Chinese settlement. According to the classifications available in genetics and linguistics, Taiwan's aborigines belong to the Austronesian group, which is strongly associated with ethnic groups in the South Pacific islands, such as the Philippines, Malaysia, Indonesia, Madagascar and Oceania. Indeed, some linguists have even considered Taiwan to be the origin of Austronesian languages, giving these native languages great historical significance (Bellwood, 1991; Blust, 1985).

With the arrival of Han Chinese immigrants, the aboriginal peoples came to live on the 'frontier' of the territory of China and were viewed as 'non-Han Chinese', perceived as 
occupying a relatively low cultural level and believed to be irrational in religion and behaviour. Recorded Chinese documents show that aborigines in Taiwan were referred to as 'East Savages' or 'Wild Barbarians' (Eastern Savages) in dossiers and local chronicles. In the Qing Dynasty, they were called 'East Barbarians', 'Wild Barbarians', 'Raw Barbarians', 'Semi-subdued Barbarians' or 'Cooked Barbarians' according to their level of assimilation with Han cultural norms (Hong, 2009; Wang, 2001). During the Japanese colonial period, Taiwanese aborigines were referred to as a 'Barbarian Group' or 'Takasagozoku'. After the Chinese restoration, the government generally referred to aborigines as 'Shanbao' (the mountain compatriots). It was not until 1994 that they were officially called aborigines. The Ministry of the Interior now lists 14 groups as aboriginal tribes: Amis, Bunun, Paiwan, Tsou, Rukai, Puyuma, Saisiyat, Tao, Atayal, Thau, Kavalan, Truku, Sakizaya and Seediq. As of June 2010, the total population of aborigines is 508,380 (approximately 2.1\% of Taiwan's population) (Ministry of Interior, 2010).

\section{The Puyuma's use of magic pertaining to betel nuts}

Relative to Taiwan's population as a whole, the Puyuma are a small tribe, consisting of approximately 10,000 people. They live on the eastern side of the Central Mountains, the coastal area of the southern part of the Puyuma River, and the mountain area of the southern East Rift Valley. During the Qing Dynasty they formed eight communities, and became particularly famed in the seventeenth century. In the Kangxi and Qianlong periods, Beinan, the head tribe of the Puyuma, defeated the remnants of the Zhu Yigui and Lin Shuangwen rebel groups. Their chief was granted court dress and given the title 'The Great Lord Puyuma' (Historical Records Committee of Taidong County, 1963; Song, 1998). The Puyuma people possessed strong military prowess because all males undertook a training system known as palakuan.

Puyuma is a matrilineal society that is characterized by uxorilocal marriage. However, this tradition has inevitably had to evolve over time. Most marriages now follow the patriarchal principles that women marry into men's families and children take their father's last name, although in some families half of the children take the mother's surname (Song, 1998; Temporary Investigating Committee on the Old Customs of Taiwan, 2000). In Puyuma society, there have traditionally been two key persons - one is the male priest who takes charge of major tribal rites and the other the political head, a role that is often assumed by someone with strong leadership qualities within the tribe who is able to take responsibility for mediating in major tribal affairs and leading hunting, tribal rites and battles. Nowadays, the male priest still retains his traditional role and is respected by the tribe, but the position of the political head has changed and can now be affected by interference from the modern governmental system (Song, 1965; Wei, 1965).

The most famous cultural figure is the Puyuma shaman, known as bulingow in Zhiben dialect, and tamaramau in the dialect of the Nanwang tribe. All neighbouring aborigines were traditionally fearful of the shaman's magic powers, and especially their supposed ability to engage in witchcraft. The shamans (usually the role was performed by women) have the ability to divine, cast spells and dominate rites, while the wizard often works as a bamboo divinatory, something that might have been learned from the Amis. Witches and wizards hold an esteemed position in Puyama society, such that it became customary for specific Puyuma women to learn witchcraft and go through the basic procedures of magic learning. A shaman performs a wide range of functions, mainly in regard to healing the 
sick, dispelling evil spirits and praying for blessings, but also assisting people searching for lost property or livestock and dispelling misfortune or calling upon the spirits (Cauquelin, 2004). Nowadays, the tribe still preserves the traditional shaman for helping with illness, dispelling evil spirits and executing the customs and ceremonies related to significant life events. It should be noted that magic is further sub-divided into white and black magic. The former focuses on healing the sick in order to drive out misfortune whereas the latter, rarely exercised unless regarded as absolutely necessary, is used to cast spells upon people for evil intentions (Tian, 2002).

The betel nut is famously known as a key medium for sacrifice in Puyuma witchcraft and various rites. Without it, it is believed, people would have lost the means to communicate with the ancestral spirits. The term palisian means 'casting spells or performing rites', which is called salisin by the Amis. In the early days of society, when people confronted perceived injustice without strict laws to follow, the function of casting spells came into existence. Particularly during times of battles between tribes, Puyuma witchcraft worked to aim evil spells at the enemy and counteract or diminish the opponent's magic powers. Now only the aged shamans possess this mysterious skill, and it is rare for people to perform such black magic.

An intact betel nut without any cuts made to it represents the fact that the ancestral spirits have not yet been requested. Three betel nuts split open with string-tied pottery beads, or with iron slivers inserted, represent the fact that the ancestral spirits have already been requested. The Puyuma take the shape of the betel nut to symbolize a person, with the stalk tip representing a human head and the fruit the human body. They cast a spell upon part of the target person, and believe the power of the spell will be enhanced if pottery beads or slivers of iron are inserted into the betel nut (Baisu, 2010; Zeng, 2009).

The Amis, the largest aboriginal group in Taidong, also engage in magic practices. Many tribes will ask for guidance from spirits through cikawasay (wizards), who may use methods as varied as dreams, bird divination or 'edaw (bamboo divination). The wizards perform 'edaw by stepping on the middle of a slim bamboo branch and dragging both ends of it. They claim to tell fortunes according to the shape of the crack that appears, and use it to dispel evil spirits, heal illness or resolve confusion. However, unlike the Puyama, the Amis practice the ritual for their own benefit, rather than for harmful purposes (Lin, 2005; Yang, 2003).

\section{The first recorded victims - Hongye baseball team}

The aborigines' connection with baseball dates back to the Japanese colonial period, during which the first all-Amis baseball team was formed in 1921, in an attempt to civilize them and stop their violent behaviour (Xie \& Xie, 2003; Yu \& Zeng, 2004; Yu et al., 2006). This was followed by the famous Jianong baseball team, which included several key indigenous players who took the team to runner-up status in the 1931 Koshien finals, held in Japan (Lin \& Lin, 2005; Zeng, 2001). After the KMT came to Taiwan, Taidong's baseball continued to thrive under the tutelage of Jianong alumni - most of whom were Amis, with a few Puyuma.

Despite a long and rich history of baseball involvement, the importance of folk religion, including Puyuma betel nut magic, is largely ignored in Taiwan's scholarship. Zhang Jingguo's (1983) edited book was arguably the first recording of the relationship between baseball and witchcraft in print. Strangely, however, the specific 
contribution that featured the most controversial incident was anonymous, thus making it hard to trace its origin. The essay mentioned the legendary stories of the Hongye team, who won against Japan's Kansai all-star team in 1968. They lived such a Cinderella tale that some even claimed Hongye was the starting point of Taiwanese baseball. However, the author was more intrigued by their altercation with Puyuma over black magic.

The scene was set in the Hongye village inhabited by the Bunun, with the Puyuma as visitors. In the past, the two tribes had their own territories and fought many battles, in which they demonstrated profound hatred towards each other. They even had the custom of hunting their rivals' heads (Kasahara, 2009). It was not until Puyuma chief Ma Zhili successfully brokered a truce between his people and the Bunun in 1939 that two centuries of mutual killing came to an end. After generations of pacification under Japanese rule, the two tribes gradually acquired a more forgiving attitude towards one another, and are now no longer engaged in hostilities (Sun, 2001).

For 10 years prior to becoming principal of Hongye Elementary School, Lin Zhupeng worked as the Director of Teaching Affairs in Beinan Elementary School, dominated by Puyuma children. He started the baseball team in Hongye and first brought the children down from the mountains to play friendly games with Beinan in 1963. However, many Hongye children developed diarrhoea. Parents suspected the cause was an evil spell cast by the Puyuma during ball games. As a result, parents refused to allow their children to play baseball. This placed Principal Lin in a difficult situation. He tried his best to explain to the parents that in modern times, with advanced scientific knowledge, witchcraft or spells were not to be taken seriously; however, the Hongye villagers were reluctant to believe Lin, and training was suspended less than two months after the team had been formed.

To find out the real cause of the problem, Principal Lin invited Cai Wenshui, the chief doctor from the health station of Yanping Township, to carry out medical checks on all the team members. The result showed that the diarrhoea had been caused by roundworm and hookworm. In response, Lin not only asked Cai to help provide medicine to the students immediately, but also bought flour to make buns in order to provide them with nutriment. Thanks to his efforts, the students gradually recovered. Parents ceased to fear some mysterious power and ultimately, with everyone's approval, the team resumed training and competing.

This story is the only written record of witchcraft within baseball. Though it does not mention betel nuts in terms of performing black magic, the account vividly demonstrates how fearful Bunun were of the Puyuma, especially when bad things occurred. When asked about this event, Lin replied: 'They were suspicious of their plot, but I strongly insisted that it was not witchcraft. If they did really want to cast the spell, why not cast it on me, the principal?' (personal communication, August 14, 2010). In fact, students were even sent to a Puyuma doctor, whom the parents had previously thought of as belonging to the forces of evil, to have comprehensive health checks; they quickly recovered. Although the journalist recounting this story claimed that team training was halted due to witchcraft, this was not true. The team carried on with their training schedule without it being affected by the incident. It is assumed that the reporter dramatically exaggerated this event to generate higher sales.

According to $\mathrm{Hu}$ Meiyun, a first-generation Hongye player, 'Bunun and Puyuma indeed had some conflicts over the occupied territory, and both peoples had the custom of hunting the others' heads'. As for the suggestion that spells were cast on the Hongye 
baseball team, he stated, 'I think it was because of the poor sanitary conditions at that time ... It happened when we lost to Beinan, so parents started to blame it on witchcraft. It was a coincidence' (personal communication, August 9, 2010). However, Hu did admit that Puyuma witchcraft was famous and that he would make a detour if he saw a betel nut on the path.

\section{Personal experiences of betel nut and baseball prior to 1972}

In interviewing Amis coaches, the researcher found that they unanimously agreed about perceptions of the wicked, yet unbelievable, magic power of betel nuts during their childhood. Guo Zixiong, a retired Amis coach, remembers: 'They love to use betel nuts with beads inserted, and then put them there... I saw a lot of this in my childhood and on the curbs of roads. It was strange... We dared not to walk over the nuts; instead, we took a bypass' (personal communication, February 2, 2010). A senior baseball player, Gao Kewu, commented: 'We were very naïve when we were small, and always thought if people were sick, we should go for a Puyuma witch for healing them' (personal communication, 9 August, 2010). Here we see the typical stereotype of Puyuma witchcraft projected by the Amis people.

Former baseball player Chen Mingtian also had an unforgettable experience of witchcraft in baseball:

I was playing baseball with bare feet in my elementary school time. I made a hit and ran across the bases but sprained [my foot] because of the poor field. My big toe swelled badly ... Till the third day, I was so much in pain that my mother went for a relative, a Puyuma witch. She started her witchcraft by setting six fresh betel nuts on the ground and began her incantation. She walked into the river, and when walking back, she was breathless and sweating badly. Suddenly, a thing dropped - a dried flat betel nut with beads and a needle in it. She had fought with the evil figure setting up the poisonous spell and finally she defeated it. The next day, my swollen toe was cured without taking any medicine (personal communication, 3 February, 2010).

In relation to the baseball games themselves, it was not until the late 1960s that betel nuts were found in the field. In the 1960s and 1970s, Beinan and Xinsheng Junior High Schools were in close proximity to each other, and fierce rivals for district supremacy. The former is located in Beinan region, and therefore had more Puyuma players; the latter is located in Taidong City and contained more Amis. Geographically, Taidong County Public Athletic Field was closer to Xinsheng Junior High School than to Beinan. Chen Mingtian, a former player from Beinan Junior High School, recalled one curious incident:

Our coach asked us to clean up the field before the following day's competition. When we took off the home plate to draw lines, we saw betel nuts, about four or five; they were fresh, not dry at all. We stripped the nuts and found three beads and a needle inside. We also found more betel nuts under the pitcher's mound. Damn it! Some of the aborigines said this is salisin. They started cursing and threw the betel nuts into the bush without telling the coach or others, to make them believe the betel nuts were still in the field (personal communication, 3 February, 2010).

The coach of Xinsheng, Wang Jincheng, however provided a rival suggestion of who was responsible for burying the betel nuts. He mentioned that every time his team played Beinan Junior High School, whose Puyuma players accounted for a higher percentage of the student body, they found betel nuts. Therefore, Xinsheng players always arrived on the field 30 minutes early, with the stated purpose of cleaning the field but in reality to dig out the betel nuts that might have been buried there, because the parents of players had told 
them to avoid injury (personal communication, August 13, 2010). In their view, the betel nuts represented evil intentions towards people. While other respondents only witnessed this form of behaviour a small number of times, Coach Wang experienced it all the way from junior high to senior high in his playing career, especially in regional competitions where opposing teams included Puyuma players or coaches.

Amis player Yang Jieren recalled that when they participated in the Taidong Little League competition in 1972, they lost a game to a team that included several Puyuma players. Parents said the match was cursed and later took off the bases to see if there had been foul play. They found betel nuts under every base (first base, second base, third base and home plate) and also the pitcher's mound. At that time, the bases were not located permanently on the ground but fixed by two nails. The people who buried the betel nuts must have spent some time pulling out the nails and then digging holes to put the nuts in. Since the nuts were found after the game, they were dried out and beads were strung through them with a thread. At the time, Yang and his teammates genuinely believed that they had lost the game because of black magic, and protested this loudly (personal communication, 12 August, 2010).

\section{The 'magical' journey of the 1994 Beinan Junior High School baseball team}

The betel nut spell seemed to vanish between 1972 and 1994, a major reason for which was the player exodus that resulted in many Taidong players going to play in other cities or counties and the dissolution of local teams. With no team playing in Taidong, fears about the betel nut spell disappeared. But in 1990, the CPBL (Chinese Professional Baseball League) was established, offering a future for grassroots players. At the same time, the Ministry of Education launched the student baseball league, in which players were not allowed to play for any city or county other than their own place of origin. In addition, Nanwang Elementary School won the Chinese Cup Youth Baseball Tournament with a team of graduates from Beinan Junior High School. Puyuma coaches Chen Zhixiong and Chen Fubin, from Nanwan, were hired to provide coherent training for the players. In 1994, these Taidong players fulfilled their potential in the National PONY (Protect Our Nation's Youths, for children aged 13-14) League Qualifying Tournament, in which Beinan and Xinsheng Junior High Schools came first and second respectively. Beinan subsequently represented Taiwan to win the PONY Asia-Pacific Qualifying Championship, and then went on to clinch the PONY World Series in Pennsylvania, in the United States.

Competitions between the two Taidong teams of Beinan and Xinsheng Junior High Schools were often tense affairs, to say the least. As such, both sides called for help from mysterious powers - which was, by that time, a highly unusual phenomenon. Xinsheng included Amis players from the coastal area, who had better stature. They were viewed as the superior team, especially since they had the six-foot Amis pitcher Chen Yuanjia. Beinan's players were mostly from the mountains and were smaller in stature than the Xinsheng players. However, they were well-trained. In May 1994, Xinsheng clinched the championship, while Beinan only attained third place in the National Under-15 Rubber Baseball Tournament. But the most important competition was the PONY League Qualifying Tournament, held in Taichung, where a double-elimination system was used. Although Xinsheng were seen as favourites to win the competition, surprisingly, they lost to Beinan in the first game. As a result, they went for the repecharge and had to fight their 
way back into contention, beating opponents one by one until they ultimately met Beinan again in the final. Xinsheng's parents started to question whether a curse had been the cause of their initial failure, particularly as they had seen a Puyuma witch in the stand. As Guo Zixiong, the coach of Beinan, recalled:

As soon as Xinsheng lost [the first match], they started to blame it on the spell from Puyuma. The coach's wife of Xinsheng was from Nanwan, Puyuma, so he insisted there were mysterious power involved. [In the final], the first base referee asked why you aborigines brought two god statues on the spectator stand... Those statues of Daoist gods were brought by parents from Xinsheng to counteract the Puyuma witchcraft. ... I asked them again why they brought two god statues?... They replied it was all because the Puyuma people love using salisin. I burst out laughing... I told them it was their tradition, but not mine. I said to them that they needed to bring a god who can play baseball. The gods they took don't know about baseball, so how could they win the game? (laughing wildly) (personal communication, 2 February, 2010).

In what is related above we can see evidence of the transformation of belief systems amongst the Amis, who had replaced animism with Daoism as a consequence of rapid Han Chinese assimilation. Most people in the Malan tribe, one of the biggest Amis gatherings in Taidong, have converted to Daoism. Not surprisingly, therefore, several Xinsheng parents were willing to carry the prosperity-dispersing Queen Mother of the West (Xi Wangmu) to suppress the Puyuma witchcraft which had become a common conversation topic amongst the locals. Lu Guanchang, a Xinsheng player, recalled that the Goddess was placed on a deity table, and set at the entrance of the dugout facing the opponent team and they started incense worship. After that the Goddess was moved to the stand. He jokingly recounted that the statue arrived late for the game and therefore could not exert her mighty power from the very beginning, meaning the team lost the game 0-7 to Beinan (personal communication, 28 August, 2010).

The Queen of the West-versus-Puyuma witchcraft showdown created a hangover that lingered for over a year. Parents from both sides accused each other of a number of things, even to the level of committing acts of sacrilege towards their opponents' gods. The entire event was reported in the press and later hindered an organized effort to form a Taidong all-star team to compete at the IBAF (International Baseball Federation) Under-16 Tournament in 1995. Neither side would make any concession to the other; the County Government had to mediate in order to merge both sides into a dream team, which subsequently clinched the national championship. Ironically, when the players from both sides graduated one year later, they entered the same high school, Taidong Sports High School. The grudge between them gradually diminished.

Both Puyuma coaches brought betel nuts on their trips overseas to compete in the PONY Asia-Pacific Qualifying Championship in Japan and the PONY World Series in the United States. Officially, a betel nut may not be carried abroad; however, the coaches divided the nuts into five parts and had students carry them separately, thus circumventing the customs inspection. Gao Wei remembers: 'We were afraid when inserting those betel nuts into our luggage, for in the States, they had police dogs to smell and search for contraband. Luckily, we passed all examinations' (personal communication, 3 August, 2010). The betel nuts were not only to be chewed, but also used to improve performance in ball games. Indeed, before the team took off, the betel nuts had been sent to witches, who endowed them with magical powers that would enable them to function in Japan and the United States.

The Amis coach, Guo Zixiong, did not believe that the supposed magic power of betel nuts could help the performance of the team. But he remains convinced that his Puyuma 
counterparts continued to use the enchanted betel nuts, carrying them to America and burying them in the ballpark:

I was joking to a Puyuma coach saying will their god travel with us all the way to the States? He answered he had already called back home to ask the witch and confirmed that the magic power would still work. I could have set my face against this, but I chose to respect them ... When the betel nuts were buried, those Americans certainly didn't know what they were doing. They pretended they were practicing but actually let students and pitchers go digging holes to put the nuts in... So the magic power seemed to go with us to the States and help Beinan win the World Series (personal communication, 2 February, 2010).

Although the Amis coach asserted that Puyuma coaches did execute the mysterious spell by burying betel nuts under the pitcher's mound and batter's box, this was denied by Beinan pitchers Gao Wei and Luo Jianming: they said that while their coaches did bring betel nuts to the States, they buried them outside of the dugout for players to walk across, simply for good luck. They sought to use the nuts in a positive way, not to curse or call up evil spirits. Perhaps as the Amis coach was overly familiar with tales of Puyuma witchcraft, he thus had a stereotypical view that the Puyuma must have won the game by means of the spell. Alternatively, perhaps the Puyuma coaches did secretly set up the betel nut spell, but it was not discovered by others.

\section{Coaches' and players' reflections on magic}

Recently, it has been rare to hear of betel nut spells, and young players do not find these items buried on the field. However, the betel nut can still be used as a medium to pray for good luck. Tian Zhijia, a Puyuma player who once played for Zhongdao High School, mentioned that their head coach was also a Puyuma, and there was always a dried betel nut attached to their team flag. If the game was close, and especially if the team fell behind in the seventh inning, the head coach would start to mumble aboriginal spells towards the flag. 'He looked so serious that no one dared to bother him. Not a single person had the slightest idea of what he was mumbling about, but strangely enough, the game would end up with a draw, and sometimes a win!' (personal communication, 4 August, 2010). Interestingly, 10-year-old Zhongdao was knocked out during the early group stage in virtually every national competition, despite calling for blessings from 'ancestral spirits'.

All the Amis coaches, past and present, refute the supposed effect of betel nuts and regard this as nonsense with no scientific backing. Moreover, due to repeated references to dreadful Puyuma witchcraft by their forefathers, most Amis think burying betel nuts must be evil, characterized by the negative intention of injuring an opponent or making him unable to hit well, instead of the more common practice of using them praying for good luck. During the 1960s and 1970s, the Malan baseball team, which was composed wholly of Amis players, had its own fixed rite before setting off for a game. The male elder started the rite by reading the Amis curse, calling upon their ancestral spirits to keep their offspring safe during the game. This rite involved praying for blessings rather than evil intentions. Additional to this was bamboo divination. The Amis elder would step on the middle of a slim bamboo branch and drag both ends of it; he could foretell the team's future performance in accordance with the shape of the resultant crack.

Yang Jieren insists that betel nuts had no power over the results of games: 'If they did, the games would not have gone so smoothly, and besides, no players were hurt during the game' (personal communication, 12 August, 2010). He suggests, however, that players were so upset about losing vital games that they thought that the betel nuts had affected the 
match outcome. Chen Mingtian also recalls that 'Beinan and Xinsheng both had their winning and losing periods, and no one was hurt, so nothing was really influenced by magic' (personal communication, 3 February, 2010) and Wang Jincheng dismisses Puyuma witchcraft, saying that 'though the magic may only succeed once in ten times, everyone would remember the successful one' (personal communication, 13 August, 2010). The 18-year-old Puyuma player Chen Zhenghao developed a similar understanding while playing for the Nanwang youth baseball team:

The witch would talk to us first in Mandarin, which was very fluent. She said the ancestral spirit of Beinan would bless and protect us in our baseball games. Then she asked us to walk to an open ground, and placed some sand on the grass, and put betel nuts on it. Three nuts on one side, so both sides had six. She also inserted beads into them. Then she made us stand in front of the nuts and spoke to us. However, we still lost games. I think that rite was only for mental calmness, nothing more (personal communication, 5 February, 2010).

The interviews with coaches and players revealed that Han Chinese people did not really believe in or even know about Puyuma witchcraft. For example, Lin Zhupeng and $\mathrm{Fu}$ Qingshun, the key figures in the promotion of school baseball in Taidong and both former school principals, did not know of it. Guo Guicai, a coach and a follower of Daoism, did not believe in it either. Most Han people have had limited dealings with the Puyuma, so are far less wary about witchcraft than other aboriginal groups.

To date, no Puyuma coaches have admitted that they buried betel nuts. This could be because using black magic was not something to be proud of, or because it was not the coaches who engaged in this practice. Some people think the victory-obsessed parents may have had recourse to the nuts. In fact, winning a baseball game is based on science and training. If a coach does something against this principle, it would certainly backfire once the results did not go their way. As a Puyuma coach put it, 'if witchcraft does have such a powerful effect, then players don't have to practice anymore; all they need is to bury betel nuts for the results' (personal communication, 5 August, 2010).

The lower a person's level of education, the more likely it might be that they believe in magic; people with a higher educational background are more inclined to see magic as a baseless pseudo-science that has no place in baseball. Taiwan did not adopt a nine-year compulsory education system until 1968, so most aboriginal parents had only received elementary school education when the betel nut incidents occurred. Their desire for national success, bringing fame and the prospect of their children playing abroad, was very strong - unsurprisingly, considering the poor and marginalized state of Taidong county.

\section{Conclusion}

To Puyuma people, the betel nut is a seed that creates a chewing tobacco-like high, but is also a tool of worship in their traditional rites. It is more important than rice wine because it acts as a medium that communicates with ancestors and gods. This essay has sought to analyse the symbolic meaning and cultural practices associated with the betel nut spell in baseball from the viewpoint of cultural anthropology, through empirical data collected through fieldwork and existing secondary materials. For historical reasons, different groups of people have different interpretations of cultural symbols. For example, all Amis think burial of the betel nut is motivated by malicious rather than positive intentions. In addition, they assert that betel nuts are an essential accessory of the Puyuma, who cast evil spells secretly. By contrast, the Puyuma claim that the betel nut is used only for benign 
prayer, as well as for chewing, thus denying completely the evil aims that are thought by others to lie behind their use of the nut. In the cases above it seems likely that Puyuma parents buried nuts secretly, with coaches giving silent consent. When their opponents found the betel nuts, they tended to blame the Beinan coaches.

As the government gradually opened up educational opportunities to a wider section of the population, baseball players' performances were increasingly regarded as reliant on scientific training, whilst witchcraft was viewed as a superstition with no scientific basis. Anyone seeking to challenge this principle through the use of magic power would almost certainly be ridiculed by others, resulting in a negative influence on the team. Although the practice had the significant effect of reinforcing negative feelings towards the Puyuma amongst other aboriginal tribes, no betel nuts have actually been found buried in the field since 1994.

It would be rash, however, to conclude that in Taiwan, as elsewhere, the use of superstitious ritual in sport has been an inevitable casualty of the development of the sport sciences. As Malcolm (2011, p. 292) notes, 'Given the specifically modern, multilayered way in which athletes conceive of time, it is somewhat paradoxical that the well-documented drive toward the scientization of sport... has not entirely removed "magical-mythical"”.

Like deep-sea fishing in treacherous conditions, 'sport, by nature, requires a sense of belief and self-efficacy that one can perform well and accomplish tasks' (Wright \& Erdal, 2008, p. 197). Indeed, research has shown that 'widespread superstitious behavior among baseball players can be attributed in part to the perception that outcomes in the sport are often the result of uncontrollable forces' (Burger \& Lynn, 2005, p. 76). It is in this context that we need to understand the role not only of sport science, but also of magic and seemingly irrational belief systems. Schippers and Van Lange (2006, p. 2550) suggest that 'although the enactment of superstitious rituals often does not make sense to observers, it may serve an important tension-regulation function for sportspeople prior to a match'. It is undeniable that magic and superstition could play a useful role, especially in preEnlightenment cultures in which modern science is at an embryonic stage far removed from the elevated status that it holds today. To recognize this, however, is not necessarily to endorse the claim that the sport sciences, particularly sport psychology, offer more to athletes than the superstitions of the past. Just like the latter, their function is primarily to instil confidence in uncertain times - and that, when all is said and done, is precisely what the betel nut spell offered to Puyama baseball players.

\section{Acknowledgements}

This study was supported by a grant from National Taiwan University of Physical Education and Sport (100DG00115).

\section{References}

Baisu, L. (2010). Yuanzhumin zazhi: 'edaw zhuzhan [News and Magazine of aborigines: 'edaw bamboo divination]. Taiwan Lihpao, http://www.lihpao.com/?action-viewnews-itemid-5866.

Bellwood, P. (1991). The Austronesian dispersal and the origins of languages. Scientific American, 265(1), 88-93.

Bleak, J. L., \& Frederick, C. M. (1998). Superstitious behavior in sport: Levels of effectiveness and determinants of use in three collegiate sports. Journal of Sport Behavior, 21(1), 1-15. 
Blust, R. (1985). The Austronesian homeland: A linguistic perspective. Asian Perspective, 26(1), 45-67.

Bradley, M., \& Gordon, D. (2007). Haunted baseball: Ghosts, curses, legends, and eerie events. Guilford, CT: Lyons Press.

Bradley, M., \& Gordon, D. (2010). Field of screams: Haunted tales from the baseball diamond, the locker room, and beyond. Guilford, CT: Lyons Press.

Burger, J. M., \& Lynn, A. L. (2005). Superstitious behavior among American and Japanese professional baseball players. Basic and Applied Social Psychology, 27(1), 71-76.

Cauquelin, J. (2004). The aborigines of Taiwan. The Puyuma - From headhunting to the modern world. London: Routledge.

Ciborowski, T. (1997). "Superstition" in the collegiate baseball player. The Sport Psychologist, $11(3), 305-317$.

Frazer, J. G. (1993). The golden bough: A study of magic and religion. Ware, UK: Wordsworth Editions.

Gao, Z. (1995a). Yuanzhu min yu taiwan bangyun (1) [Aborigines and Taiwanese baseball (1)]. Shanhai wenhua shuang yuekan [Taiwan Indigenous Voice Bimonthly], 9, 32-36.

Gao, Z. (1995b). Yuanzhu min yu taiwan bangyun (2) [Aborigines and Taiwanese baseball (2)]. Shanhai wenhua shuang yuekan [Taiwan Indigenous Voice Bimonthly], 10, 26-30.

Gardiner, E. N. (1925). Olympia: Its history and remains. Oxford: Oxford University Press.

Gmelch, G. (1971). Baseball magic. Society, 8(8), 39-41.

Gmelch, G. (1992). Superstition and ritual in American baseball. Elysian Fields Quarterly, 11(3), $25-36$.

Gmelch, G. (2009). Baseball magic. Sociology 101, retrieved July 5, 2010 from http://sociology 101. net/readings/Baseball-Magic.pdf

Historical Records Committee of Taidong County (1963). Taidong xianzhi [General Records of Taidong County]. Taidong: Taidong County Government.

Hong, L. (2009). Shoufan shehui wangluo yu jiti yishi [Social network and collective consciousness of Cooked Barbarians]. Taipei: Lianjing chuban she.

Kasahara, M. (2009). Taiwan beinan zhu de liangge jisi [Two ancient ceremonies of Puyuma tribe in Taiwan]. (S. Huang, Trans.) Dong taiwan yanjiu [Research on eastern Taiwan], 13, 95-138.

Lin, B., \& Zhu, Z. (2009). Huadong bangqiu yu yuanzhu min [Baseball and aborigines in Hualian and Taidong]. Yundong wenhua yanjiu [Studies in Sports Culture], 9, 67-108.

Lin, E. (2005). Yi daba liujiu buluo de shijian jingyan chujian beinan zu wushu de lilun [The fundamental theory construction of wizardry in Puyuma tribe based on the actual experience in Damalakaw]. (Unpublished master's thesis). National Tainan University, Tainan, Taiwan.

Lin, H., \& Lin, M. (2005). Diancang Taiwan bangqiu shi: Jianong bangqiu [The Classical Collection of Taiwanese Baseball History: Jianong Baseball Team]. Taipei: Sports Affairs Council.

Malcolm, D. (2011). Sport medicine, injured athletes and Norbert Elias's sociology of knowledge. Sociology of Sport Journal, 28, 284-302.

Malinowski, B. (1954). Magic, science and religion, and other essays. Garden City, NY: Doubleday.

Ministry of Interior (2010)., http://sowf.moi.gov.tw/stat/month/m1-08.xls.

Neal, G. I. (1982). Demystifying sport superstition. International Review for the Sociology of Sport, $17(1), 99-124$.

Qiu, W. (2003). Shi suolian haishi yuyi: Yuanzhu min bangqiu xuanshou de yundong zhilu [Chains or wings: The sporting path of aboriginal baseball players]. (Unpublished master's thesis). National Hualien Teachers College, Hualian, Taiwan.

Qiu, Y. (2008). Shehui jiegou yinsu yu yuanzhu min yundong xuanze zhi tantao: Yi bangqiu yundong weili [Social structures and the choice of aboriginal movements-A study based on baseball sport]. (Unpublished master's thesis). Yuan Ze University, Xinzhu, Taiwan.

Rudski, J. M., \& Edwards, A. (2007). Malinowski goes to college: Factors influencing students' use of ritual and superstition. Journal of General Psychology, 134(4), 389-403.

Schippers, M. C., \& Van Lange, P. A. M. (2006). The psychological benefits of superstitious rituals in top sport: A study among top sportspersons. Journal of Applied Social Psychology, 36(10), 2532-2553. 
Song, L. (1965). Nanwang cun beinan zu de huisuo zhidu [The Puyuma Youth Training System in Nanwang Village]. Kaogu renlei xuekan [Journal of Archaeology and Anthropology], 25/26, $112-144$.

Song, L. (1998). Taiwan yuanzhu min shi: Beinan zhu shipian [The History of Taiwanese Aborigines: The History Article of Puyuma]. Nantou: Historical Research Commission of Taiwan Province.

Sun, M. (2001). Ma Zhili [Ma Zhili]. In H. Wang (Ed.), Taidong xianshi: Renwu pian [The History of Taidong County: Articles on Figures] (pp. 210-211). Taidong: Cultural Center of Taidong County.

Temporary Investigating Committee on the Old Customs of Taiwan (2000). Fanzhu guanxi diaozha baogao shu dier juan amei zu beinan zu [The Investigation Report on Customs and Habits of Barbarian Ethnic, Volume 2, Amis and Puyuma]. Taipei: Institute of Ethnology Academia Sinica.

Tian, Z. (2002). Taiwan de yuanzhu min: Beinan zu [Taiwanese aborigines: Puyuma]. Taipei: Taiyuan chuban she.

Wang, H. (1994). Hongye de gushi. [The Story of Red Leaf]. Taipei: Minsheng bao.

Wang, S. (2001). Taiwan yuanzhu min de shehui yu wenhua [Aboriginal society and culture in Taiwan]. Taipei: Lianjing chuban she.

Wei, H. (1965). Taiwan tuzhu shehui de buluo zuzhi quanwei zhidu [The Tribal Organization and Authoritative System in Taiwan's Indigenous Society]. Kaogu renlei xuekan [Journal of Archaeology and Anthropology], 25/26, 71-87.

Wright, P. B., \& Erdal, K. J. (2008). Sport superstition as a function of skill level and task difficulty. Journal of Sport Behavior, 31(2), 187-199.

Xie, S., \& Xie, J. (2003). Taiwan bangqiu yibai nian [One Hundred Years of Baseball in Taiwan]. Taipei: Guoshi chuban she.

Yang, J. (2003). Mukiangai: Jianhe beinan wushi de yishi shijian [Mikiangai: The rites and practices of Puyuma wizards in Jianhe], (Unpublished master's thesis). National Tsing Hua University, Xinzhu, Taiwan.

Yu, J. (2007a). Playing in isolation: A history of baseball in Taiwan. Lincoln, NE: University of Nebraska Press.

Yu, J. (2007b). The Hongye legend in Taiwanese baseball: Separating myth from reality. The International Journal of the History of Sport, 24(10), 1264-1280.

Yu, J., Tang, S., Zeng, W., Jia, Y., Xie, S., \& Xie, J. (2006). Xuandong suiyue: Taiwan bangqiu bainian shi [History of Baseball in Taiwan 1906-2006]. Taipei: Chinese Taipei Baseball Association.

Yu, J., \& Bairner, A. (2010). Schooling Taiwan's aboriginal baseball players for the nation. Sport, Education and Society, 15(1), 63-82.

Yu, J., \& Bairner, A. (in press). Confucianism, baseball and ethnic stereotyping in Taiwan. International Review for the Sociology of Sport. Retrieved from http://irs.sagepub.com/content/ early/2011/10/07/1012690211424483.full.pdf

Yu, J., \& Zeng, W. (2004). Taiwan bangqiu wang [Taiwan Baseball King]. Taipei: Woshi.

Zeng, W. (2001). Qishi nianqian jianong bangqiu dui de guangmang [The Sparkling Blade of Jianong Baseball Team Seventy Years Before]. Guomin tiyu jikan [National Sports Quarterly], $30(4), 50-64$.

Zeng, Y. (2009). Shengming li yu lingli de meijie wu: yu KaTatipuL beinan ren binlang wenhua weili [The medium of vitality and mana: A case study of betel nuts culture among the Puyuma in KaTaTipuL]. (Unpublished master's thesis). National Taidong University, Taidong, Taiwan.

Zhang, J. (Ed.). (1983). Zhonghua minguo shaobang qingshao bang qingnian bangqiu fazhan shishi. [The history, facts of little league baseball, junior high school baseball, and senior high school baseball in the Republic of China]. Taipei: Self-published.

Zhang, T. (2007). Taidong geji xuexiao bangqiu yundong fazhan zhi yanjiu (1945-2005) [A study of baseball development at different levels of schools in Taidong (1945-2005)], (Unpublished master's thesis). National Taidong University, Taidong, Taiwan. 


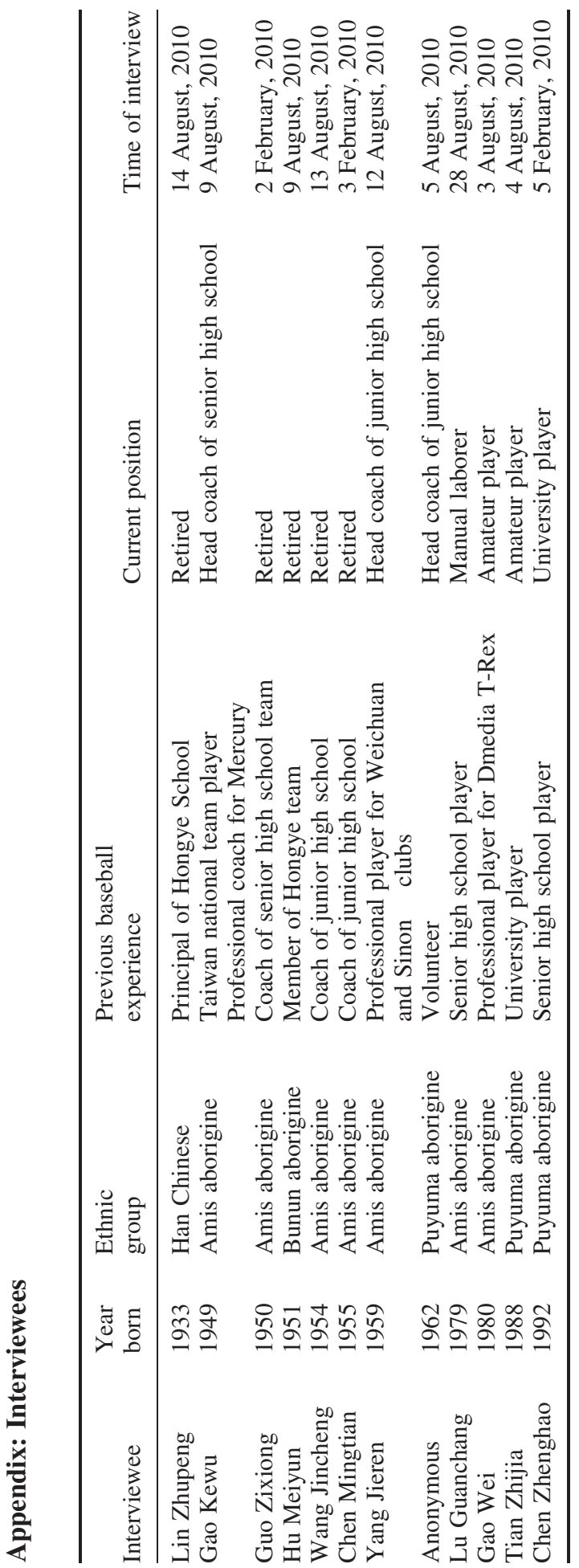

